\title{
Spot urine samples for evaluating solute excretion in the first week of life
}

\author{
Vera Matos, Alfred Drukker, Jean-Pierre Guignard
}

\begin{abstract}
Aim-To evaluate whether the urinary creatinine concentration is a reliable reference value to standardise urinary solute excretion in a spot urine sample during the first week of life.

Methods-Spontaneously voided urine specimens were obtained in 48 healthy, full term neonates, aged 1 to 6 days (median 2.4) and in 168 healthy older children with a median age of 1.5 years (range 1 month to 3 years). In $62 \%$ of the children two urine samples were available with an interval of 2 to 4 (neonates) and 7 days (older children).

Results-In neonates both the urinary creatinine concentration and the urinary creatinine:osmolality ratios were significantly higher than in the older children, and were spread over a wider range. During the first postnatal week of life the mean urinary creatinine and urinary creatinine: osmolality ratio values in the first urine samples were also significantly higher than in the second samples. In children aged between 1 month and 3 years of age, these data were remarkably stable without any significant changes between repeat urine samples.

Conclusions-The urinary creatinine concentration during the first days of life is high and variable, even when corrected for urinary osmolality. This is the opposite of what is found in older children and adults. Urinary creatinine and the urinary creatinine:osmolality ratio, therefore, cannot be used to standardise the urinary excretion of solutes in the first week of life. (Arch Dis Child Fetal Neonatal Ed 1999;80:F240-F242)
\end{abstract}

Keywords: spot urine sample; urinary creatinine; osmolality ratio; urinary solute excretion

Nephrology Unit, Department of Paediatrics, University Hospital Centre, Lausanne, Switzerland $\mathrm{V}$ Matos

A Drukker

J-P Guignard

Correspondence to: Professor Jean-Pierre Guignard

Unité de Néphrologie,

Service de Pédiatrie

Centre Hospitalier

Universitaire Vaudois

1011 Lausanne, Switzerland.

Email:

Jean-Pierre.Guignard $a$

chuv.hospvd.ch

Accepted 28 October 1998 added to the calculation. These studies were modifications of the idea first proposed by Nordin in adults. ${ }^{10}$ None of these studies has, however, shown that urinary creatinine can serve as a reliable reference standard during the first week of life. Our study aimed to answer this question.

\section{Methods}

Urine samples from 216 young children were tested. Urine samples from 48 neonates 1 to 6 days (mean 2.4) old were obtained from the University Maternity Hospital of Lausanne. The urine samples from infants/toddlers/ children from the age of 1 to 6 months $(n=38)$, 6 to 12 months $(n=41), 12$ to 24 months $(n=48)$ and 24 to 36 months $(n=41)$ were collected in nurseries and kindergartens in Lausanne.

Written, informed consent was given by all parents and the research protocol was approved by the ethics committee of Lausanne Medical School.

Only healthy, term neonates (gestational age 38 to 41 weeks) without a family history of kidney or metabolic disease were included in this study. A spontaneously voided, random urine sample was collected between 6 am and $11 \mathrm{am}$. Standard, sterile, adhesive plastic bags were used for neonates and children who were not toilet trained. In $62 \%$ of the children an additional second urine sample was obtained after 2 to 4 days (neonates/infants, $\mathrm{n}=47$, first sample, $n=33$ for second sample) or one week (all older children, $\mathrm{n}=168$ for first sample; $\mathrm{n}=76$ for the second).

The urine samples were transferred to chemically clean bottles and analysed within 3 hours. The urinary creatinine concentration (Ucreat) was determined using a kinetic Jaffé reaction (Hitachi 704 autoanalyser; reagents by Boehringer-Rotkreuz, Switzerland). The interassay coefficient of variation of this method was $<4 \%$ at Ucreat concentrations of $6 \mathrm{mmol} / \mathrm{l}$. Urinary osmolality (Uosm) was measured by freezing point depression (Microsmometer type 13, Roebling CE, Merck AG, Zurich, Switzerland).

Differences in the results between the sexes and between the two urine samples from the same child were evaluated using the Wilcoxon signed rank test. The sex data were paired for day of age. The median values of Ucreat concentrations as well as the Ucreat:osmolality ratios were compared for the 1-6 day old neonates and the older children using the Wilcoxon rank sum test. The distribution of the data are presented as box and whisker plots. The data are given as median and range; 


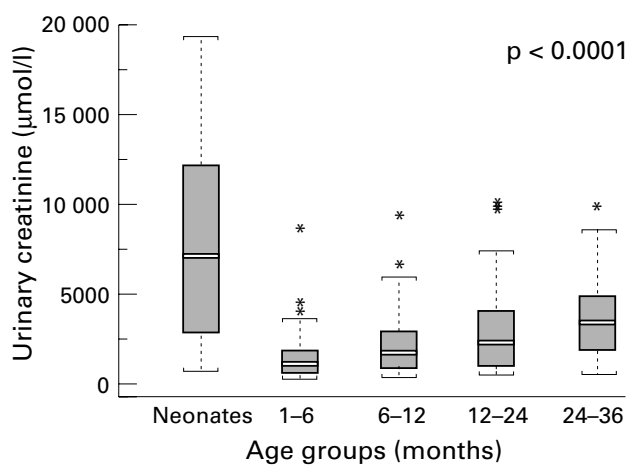

Figure 1 Box plot of urinary creatinine excretion values (Ucreat) in 48 healthy neonates and four additional groups of older children. Data are given as medians and range. Difference between neonates and other children was highly significant $(p<0.0001)$.

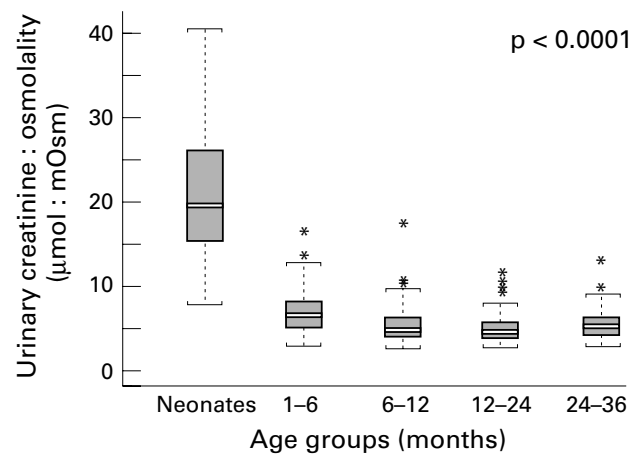

Figure 2 Box plot of urinary creatinine:osmolality ratios in 48 healthy neonates and four additional groups of older children. Data are given as median and range. Difference between neonates and other children was highly significant $(p<0.0001)$.

$\mathrm{p}<0.05$ was considered significant. For the statistical calculations the STATA 4.0 package for Windows (Stata Corp, College Station, TX, USA) was used.

\section{Results}

The median value of Ucreat in the neonates (7060 $\mu \mathrm{mol} / 1$, range 680-19300) differed significantly $(\mathrm{p}<0.0001)$ from that of older
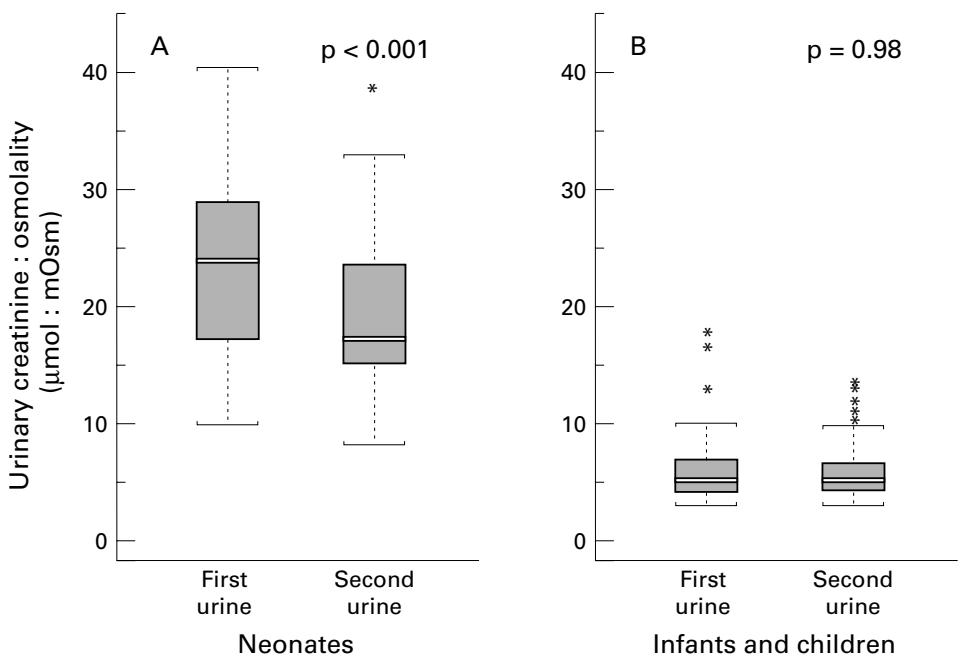

Figure 3 Box plots of urinary creatinine:osmolality ratios in two urine samples of healthy neonates (2 to 4 days apart) (A) and four additional groups of older children 7 days apart (B). Data are given as median and range. Difference between first and second urine samples in the neonates was significant $(p<0.001)$. No significant differences between the values in the two urine samples were found in the older children $(p=0.98)$. children (1961 $\mu \mathrm{mol} / 1$, range 260-9970) (fig 1). These numbers also show that the scatter of the creatinine values at birth was far greater than at a later age (figs 1-3). The mean Ucreat:osmolality ratio of the neonates was $19.7 \mu \mathrm{mol} /$ $\mathrm{mOsm} / \mathrm{kg} / \mathrm{H}_{2} \mathrm{O}$ (range 7.9-40.5) and 5.2 (range 2.7-17.6) for the older children $(\mathrm{p}<0.0001)$ (fig 2). No significant differences were found between the sexes. There was, however, a significant difference $(p<0.001)$ for both Ucreat and Ucreat:osmolality values between the two urine samples in the neonates, with the highest values found in the first urine sample (fig 3A). For those aged between 1 month and 3 years of age, both urine values were comparable and remained remarkably stable (figs 1 to $3 \mathrm{~B}$ ).

\section{Discussion}

The production of creatinine is related to total lean body mass, which generally does not change within relatively short periods of time. ${ }^{11} 12$ When serum creatinine concentrations are constant, the glomerular filtration rate (GFR) is stable and tubular secretion and reabsorption of creatinine (in health at most ages) is minimal, the rate of elimination of creatinine from the body does not fluctuate very much. This steady state is the rationale for using the Ucreat concentration as a reference standard for the chemical analysis of a spot urine. ${ }^{13}$ The urinary solute:creatinine ratio was therefore considered to be a rather useful and reliable tool both in children and adults, as well as non-invasive, convenient, sensitive and relatively inexpensive..$^{1-5}$

Our study set out to ask whether the Ucreat is indeed stable in the early neonatal period. The results clearly show that this is not the case. The mean Ucreat concentration was significantly higher in neonates than in older children (fig 1). This difference remained almost unchanged when the Ucreat concentration values were corrected for changes in urine dilution and concentration by factoring Ucreat by Uosm (fig 2). More important, however, is the great scatter in the Ucreat:osmolality ratio values during the first week of life and the significant fall in these values within 48 hours (fig $3 \mathrm{~A})$. This contrasts with the picture seen in older children and adults. The latter also tend to have a large scatter in Ucreat due to wide variability in urinary volumes. At that age the influence of volume changes can be minimised after factoring the Ucreat data with Uosm. Recently Moore et al ${ }^{14}$ proposed a validation of this approach for the screening of albuminuria in spot urine samples of adult patients with correction by the specific gravity of the urine sample. As shown by us, these forms of corrections are, however, not valid in the immediate newborn period. A similar impression was reported by Karlsson et al ${ }^{15}$ when studying urinary protein excretion in neonates.

We would have preferred to compare the reported spot urine results with normal data obtained by complete, timed urine collections. This would have been the ultimate proof of our assertion that Ucreat is an unreliable reference value in the early newborn period. This would, 
however, have required bladder catheterisation of healthy neonates, which could obviously not be undertaken. Given these ethical constraints, the correction of Ucreat by Uosm was the only practical alternative.

The scatter of Ucreat can not be explained by differences in lean body mass, because all the babies were healthy, full term newborns with birthweights appropriate for their gestational ages. Other lines of evidence may, however, shed light on our findings. It has to be remembered that creatinine is a small compound (radius $0.5 \mathrm{~nm}$; molecular weight 113 Daltons) which easily passes the placental barrier. During the first days of extrauterine life the baby's serum creatinine concentrations therefore largely represent those of the mother. This changes rapidly after birth with neonatal serum creatinine values more or less stabilising within 1 to 3 weeks, depending on gestational age. ${ }^{16-18}$ During postnatal anabolic growth muscle mass will increase, thus adding to changes in serum creatinine concentrations and urinary excretion of creatinine. Obviously, the tubular delivery and handling of creatinine also undergo rapid developmental changes, mainly due to the postnatal increase in GFR, which almost doubles within two weeks of birth in term neonates, with a slightly slower change in premature infants. ${ }^{19-21}$ Tubular handling of creatinine in healthy neonates is also different from that in older, more "mature" individuals. In the very young, and in particular in premature neonates (human infants, newborn rabbits, piglets) creatinine seems to undergo tubular reabsorption. This is probably due to "back-leak" of creatinine across the highly permeable "immature" luminal and basolateral tubular structures. ${ }^{22}$

The striking variations in urinary creatinine excretion in healthy neonates may even be exaggerated when dealing with sick full term babies, and even more so with premature infants, when hypoxaemia and circulatory failure will affect normal maturational changes in GFR. ${ }^{23-27}$

Whatever the pathophysiological explanation for the changes in Ucreat in the very young, it is very clear that the above observations undermine one of the basic assumptions for the chemical evaluation of spot urine samples in the early neonatal period: the constancy of Ucreat. We therefore conclude that factoring the urine solute concentration by Ucreat does not improve the reliability of random, spot urine examinations in the early neonatal period.

We thank Professor C Bachmann and his staff (Central Laboratory CHUV) for the measurements of urine osmolality and creatinine concentration. Professor P Hohlfeld and the nurses of his department (Obstetrics and Gynaecology, CHUV) were very helpful in organising and executing the collection of urine samples from the neonates, as were the staffs of the seven kindergartens who cooperated in this study. Professor Guy van Melle, from the Institute of Social and Preventive Medicine, guided us in the statistical evaluation of the data. We are particularly indebted to the children and their parents who agreed to participate in this study.

VM was supported by grant no 32-36574.92 from the Swiss National Science Research Foundation (SNSRF)

Supported by grant no 32-36574.92 from the Swiss National Science Research Foundation (SNSRF).

1 Kaufman JM, Martin LG, Seegmiller JE. Urine uric acid to creatinine ratio, a screening test for inherited disorders of purine metabolism. F Pediatr 1968;4:583-92.

2 Barratt TM, McLaine PN, Soothhill JF. Albumin excretion as a measure of glomerular dysfunction in children. Arch

3 Ghazali S, Barratt TM. Urinary excretion of calcium and Ghazali S, Barratt TM. Urinary excretion of calcium an
magnesium in children. Arch Dis Child 1974;49:97-101.

magnesium in children. Arch Dis Child 1974;49:97-101.
4 Manzke H, Kreudenstein PS, Dörner K, Kruse K. Quantification of urinary excretion of creatinine, uric acid, hypoxanthine and xanthine, uracil and cyclic GMP in healthy newborn infants. Eur F Pediatr 1980;133:157-61.

5 Ginsberg JM, Chang BS, Matarese RA, Garella S. Use of single voided urine samples to estimate proteinuria. $N$ Engl 7Med 1983;309:1543-6.

6 Houser M. Assessment of proteinuria using random urine samples. F Pediatr 1984; 104:845-8.

7 Elises JS, Griffiths PD, Hocking MD, Taylor CM, White RHR. Simplified quantification of urinary protein excretion in children. Clin Nephrol 1988;4:225-9.

8 Sargent JD, Stukel TA, Kresel J. Normal values for random urinary calcium to creatinine ratios in infancy. $\mathcal{F}$ Pediatr 1993;123:393-7.

9 Reusz GS, Dobos M, Byrd D, Sallay P, Miltenyi M, Tulassay T. Urinary calcium and oxalate excretion in children. Pediatr Nephrol 1995;9:39-44.

10 Nordin BEC. Assessment of calcium excretion from the urinary calcium/ creatinine ratio. Lancet 1959;ii:368-71.

11 Miller AT Jr, Blyth CS. Estimation of lean body mass and body fat from basal oxygen consumption and creatinine excretion. F Appl Physiol 1952;5:73-8.

12 Stuphen JL. Anthropometric determinants of creatinine excretion in preterm infants. Pediatrics 1982;69:719-23.

13 Vestergaard P, Leverett R, Orangeburg NY. Constancy of urinary creatinine excretion. F Lab Clin Med 1958;51:21118.

14 Moore RR jr, Hirata-Dulas, CA, Kasiske BL. Use of urine specific gravity to improve screening for albuminuria. Kidney Int 1997;52:240-3.

15 Karlsson FA, Hardell LI, Hellsing K. A prospective study of urinary proteins in early infancy. Acta Paediatr Scand 1979;68:663-7.

16 Sertel H, Scops J. Rates of creatinine clearance in babies less than one week old. Arch Dis Child 1973;48:717-20.

17 Guignard J-P, Torrado A, Da Cunha O, Gautier E. Glomerular filtration rate in the first three weeks of life. $\mathcal{F}$ Pediatr 1975;87:268-72

18 Fawer C-L, Torrado A, Guignard J-P. Maturation of renal function in full-term and premature neonates. Helv Paediatr Acta 1979;34:11-22.

9 Feldman H, Guignard J-P. Plasma creatinine in the first month of life. Arch Dis Child 1982;57:123-6.

20 Rudd PT, Hugues EA, Placzek MM, Hodes DT. Reference ranges for plasma creatinine during the first month of life. Arch Dis Child 1983;58:212-15.

21 Trompeter RS, Al-Dahhan J, Haycock GB, Chik G, Chantler C. Normal values of plasma creatinine concentration related to maturity in normal term and preterm infants. Intern f Pediatr Nephrol Urol 1983;4:145-8.

22 Matos P, Duarte-Silva M, Drukker A, Guignard J-P. Creatinine reabsorption by the newborn rabbit kidney. Pediatr nine reabsorption by

23 Guignard J-P, Torrado A, Mazouni SM, Gautier E. Renal function in respiratory distress syndrome. $\mathcal{F}$ Pediatr 1976;88:845-50.

24 Chevalier RL, Campbell F, Benbridge ANAG. Prognostic factors in neonatal acute renal failure. Pediatrics 1984;74:265-72.

25 Stapleton FB, Jones DP, Green RS. Acute renal failure in neonates: incidence, ethilogy and outcome. Pediatr Nephrol 1987;1:314-20.

26 Wilkins $\mathrm{BH}$. Renal function in sick very low birthweight infants: 2. Urea and creatinine excretion. Arch Dis Child 1992;67:1146-53

27 Bueva A, Guignard J-P. Renal function in preterm neonates. Pediatr Res 1994;36:572-7. 